INTERNATIONAL CENTER FOR PUBLIC POLICY
International Center for Public Policy

Working Paper 19-14

August 2019

\title{
Free Trade Agreements and World Obesity
}

\author{
Michele Baggio
}

Alberto Chong

\section{ANDREWYOUNG SCHOOL}





\title{
$\underset{\substack{\text { GeorgaState } \\ \text { University }}}{\iint_{0}} \mid \frac{\text { ANDREW YOUNG SCHOOL }}{\text { OF POLICY STUDIES }}$
}

\author{
International Center for Public Policy \\ Working Paper 19-14
}

\section{Free Trade Agreements and World Obesity}

\author{
Michele Baggio \\ Alberto Chong
}

\section{August 2019}

International Center for Public Policy

Andrew Young School of Policy Studies

Georgia State University

Atlanta, Georgia 30303

United States of America

Phone: (404) 413-0235

Fax: (404) 651-4449

Email: paulbenson@gsu.edu

Website: http://icepp.gsu.edu/

Copyright 2019, the Andrew Young School of Policy Studies, Georgia State University. No part of the material protected by this copyright notice may be reproduced or utilized in any form or by any means without prior written permission from the copyright owner. 


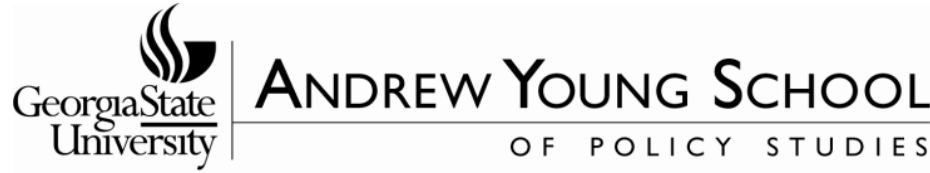

\section{International Center for Public Policy Andrew Young School of Policy Studies}

The Andrew Young School of Policy Studies was established at Georgia State University with the objective of promoting excellence in the design, implementation, and evaluation of public policy. In addition to two academic departments (economics and public administration), the Andrew Young School houses seven leading research centers and policy programs, including the International Center for Public Policy.

The mission of the International Center for Public Policy (ICePP) at the Andrew Young School of Policy Studies is to provide academic and professional training, applied research, and technical assistance in support of sound public policy and sustainable economic growth in developing and transitional economies.

ICePP is recognized worldwide for its efforts in support of economic and public policy reforms through technical assistance and training around the world. This reputation has been built serving a diverse client base, including the World Bank, the U.S. Agency for International Development (USAID), the United Nations Development Programme (UNDP), finance ministries, government organizations, legislative bodies, and private sector institutions.

The success of ICePP reflects the breadth and depth of its in-house technical expertise. The Andrew Young School's faculty are leading experts in economics and public policy and have authored books, published in major academic and technical journals, and have extensive experience in designing and implementing technical assistance and training programs. Andrew Young School faculty have been active in policy reform in over 40 countries around the world. Our technical assistance strategy is not merely to provide technical prescriptions for policy reform, but to engage in a collaborative effort with host governments and donor agencies to identify and analyze the issues at hand, arrive at policy solutions, and implement reforms.

ICePP specializes in four broad policy areas:

- Fiscal policy (including tax reforms, public expenditure reviews, tax administration reform)

- Fiscal decentralization (including decentralization reforms, design of intergovernmental transfer systems, urban government finance)

- Budgeting and fiscal management (including local government budgeting, performancebased budgeting, capital budgeting, multi-year budgeting)

- Economic analysis and revenue forecasting (including micro-simulation, time series forecasting)

For more information about our technical assistance activities and training programs, please visit our website at http://icepp.gsu.edu or contact us by email at paulbenson@gsu.edu. 


\title{
Free Trade Agreements and World Obesity
}

\author{
Michele Baggio and Alberto Chong*
}

August 2019

\begin{abstract}
We study the causal link between trade openness via free trade agreements and obesity rates. We apply a difference-in-differences approach and exploit the year a country entered a free trade agreement with the United States during the period 1990 to 2016. We find statistically and economically significant results and show that our findings are robust to placebo tests, the use of synthetic control methods, and mechanically maximizing the sample. Additionally, we show that when using event studies the equal trends assumption holds.
\end{abstract}

Keywords: Free Trade Agreements, Obesity, Cross-Country, Causality, Sugar

JEL classification: $\mathrm{H} 8, \mathrm{O} 10, \mathrm{~K} 2$

\footnotetext{
* Baggio (michele.baggio@uconn.edu): Department of Economics, University of Connecticut; Chong (achong6@gsu.edu): Department of Economics, Georgia State University and Universidad del Pacífico.

We are very grateful to Matías Busso, Angelo Cozzubo, Fernanda Estevan, Marco Gonzales-Navarro, Gianmarco León, Eduardo Lora, Vanessa Ríos-Salas and Daniel Velásquez for very useful comments and suggestions. Sharad K.C. and Tareena Musaddiq provided excellent research assistance. The standard disclaimer applies. We are grateful to Angelo Cozzubo and Joan Martinez for careful research assistance. All errors are ours.
} 


\section{Introduction}

According to the World Health Organization, world obesity has almost tripled between 1975 and 2016, rising from 4.7 to 13.1 percent. This dramatic increase in the average population weight in the world shows little signs of abatement. During this same period, free trade and economic globalization have also surged as trade openness increased from 32.9 percent in 1975 to 56.2 percent in $2016 .{ }^{1}$ Whereas some researchers - mostly in the health sciences — suspect that these two trends may be closely related, there is little formal empirical evidence to confirm this suspicion. The scarce available evidence comes mostly from anecdotes, particularly with respect to the North American Free Trade Agreement (NAFTA). ${ }^{2}$ As it is well known, this free trade agreement was created in order to reduce costs and promote trade of goods and services in North America with the ultimate aim of fostering long-lasting economic growth in the continent. This agreement was of particular importance for Mexico, which was a rather closed economy prior to NAFTA. In fact, the trade openness of Mexico increased from 30.7 percent in 1994, the year in which this agreement came into force, to 77.6 percent in 2016 , but obesity also increased from 18.4 to 28.9 percent (World Bank, 2018). Today, a substantial share of the people who are overweight and obese resides in developing countries, and the share keeps increasing along with high hunger rates, making this seemingly contradictory situation not a "rich country problem" anymore, but one that brings to the fore the extent to which free trade may be playing a role on weight-related issues in countries ( $\mathrm{Ng}$ et al. 2014; Poobalan and Aucott 2016; Miljkovic et al.,

\footnotetext{
${ }^{1}$ Trade openness is defined as the sum of exports and imports of goods and services as a share of gross domestic product.

${ }^{2}$ For instance: https://www.nytimes.com/2017/12/11/health/obesity-mexico-nafta.html
} 
The purpose of our research is to ask the question of whether free trade may cause obesity rates to increase in countries around the world, a question that to our knowledge has not been empirically studied before. To do this, we exploit the spatial and time variation in free trade agreements that the United States have signed with other countries around the world for the period 1990-2016, which roughly coincides with a boom in free trade liberalization processes and is consistent with mainstream policies fostered by both the World Bank and the International Monetary Fund as part of their structural program packages. During our period of study, 19 countries signed Free Trade Agreements (FTA) with the United States, reflected in the fact that trade openness increased from 38 percent to 56 percent during this period (World Bank, 2018). In particular, our empirical analysis employs a differences-in-differences approach and compares the prevalence of obesity rates among those countries that engaged in FTAs with the U.S. and those that did not— before and after the trade agreement was enacted. We rely on publicly available data at the country level from two sources: the World Bank and the World Health Organization.

Overall, we find that engaging in free trade agreements with the United States during our study period increases the prevalence of obesity among adults by approximately 4.4 percentage points. Furthermore, we find that obesity rates register a slight increase in the first two years after an agreement's enactment and then accelerates more dramatically. As it is well known, any causal interpretation of differences-in-differences results relies on the assumption that there should not be pre-existing trend differences in obesity rates between treatment and control group. By employing both event studies as well as synthetic control methods, we are confident that we are

\footnotetext{
${ }^{3}$ The World Health Organization estimates that currently roughly 1.9 billion adults around the world are overweight, out of which 650 million are obese. It has been estimated that 2.8 million deaths annually are attributed to obesity, and 35.8 million Disability Adjusted Life Years (DALYs) per day are lost due to obesity-related illness.
} 
able to provide solid evidence that there are no differential trends prior to trade agreement engagement. As such, we believe that the estimated effect on obesity rates can be confidently attributed to trade openness. Interestingly, our findings are consistent with standard trade theory. As open borders increase choice and reduce prices in domestic markets, the drop in prices may be so dramatic that foreign investment from firms may end up producing the unintended effect of incentivizing a shift in consumption from traditional foodstuffs (which tend to have lower fat and sugar content) to processed foods and beverages with likely higher sugar and fat content. That is, free trade and greater access to goods may lead shift food consumption habits.

In addition, we also find that the estimated increase in obesity rates tends to be larger for OECD countries, 5.1 percent, than non-OECD countries, 4.2 percent, over the sample mean. We also explore other potential key heterogeneities that may be correlated with increases in obesity rates in the world. We find that countries with a large share of young population experience a slightly larger increase in obesity rates and countries with more urbanized areas show a larger increase in obesity rates, although this difference is not statistically significant at conventional levels. Finally, we do not find any economically significant differences between genders.

In short, in this paper we find that engaging in free trade agreements with the United States during 1990-2016 increased the prevalence of obesity, likely through the increase of investment in food and beverage-related industries that helped reduce prices, which raises the question of whether free trade may not only end up exporting obesity but also, perhaps, even obesity-related diseases. Our paper is organized as follows. The next section briefly summarizes the key academic literature; the third describes the data employed as well as the empirical strategy. The fourth section presents our main results and basic robustness checks, and the final section concludes. 


\section{Literature and Likely Mechanisms}

There is little doubt that trade openness brings increased rates of economic growth, which may translate into reductions in inequality and poverty rates as well as a host of additional positive externalities. However, in recent years, public health specialists have raised the concern that obesity and international trade may also be related. While recent literature has documented the associational relationship of trade and obesity, very little is known about the causal impact between these two variables. For instance, Vogli (2014) and Costa-Font and Mas (2016) show that increases in the body-mass index in countries appear to be positively associated with both indices of economic globalization. In particular the latter find a robust positive association between trade openness and both obesity rates and caloric intake. The authors find that a one-standard deviation increase in globalization is linked with a 23.8 percentage point increase in obese population and a 4.3 percentage point rise in calorie intake. Whereas these authors attempt to correct for possible reverse causality and omitted variable bias by using a panel lagged structure as well as an instrumental variable strategy, their results remain unconvincing, mainly given the apparent lack of adequacy of the instrument employed. Along the same lines, Goryakin et al. (2015) report that economic globalization is correlated with obesity among adult women in a sample of individuallevel data covering 56 countries between 1991 and 2009. They show that their results remain robust after controlling for relevant individual- and country-level factors.

There are multiple ways that obesity rates may be rising in countries that agree to opening frontiers to international trade. Broadly speaking there are two dimensions that have been considered in the literature, an economic dimension as well as a social dimension. The former relates to the increasing economic interdependence among countries, which is related to changes in technology, opportunity costs, and prices, among others. The second pertains to cultural 
influences that may impact lifestyle and, thus, likely changes in preferences that may impact dietary habits and lifestyles (Delpeuch et al. 2009; Kawachi and Kennedy 2002; Schrecker and Bambra 2015, and others).

The economic dimension that may link free trade and obesity appears to be one related to dramatic changes in retail logistics technology, which were first observed in developed countries and have been later applied in developing countries. In particular, this mechanism is consistent with recent work on the observed increase in obesity patterns within the United States, which has been linked to the reduction in the opportunity cost of food consumption with respect to the opportunity cost of physical activity. It is directly related to the advances in retail logistics, which are reflected in massive reductions in the prices of food and other consumer goods. For instance, Courtemanche and Carden (2011) show that the entrance of Walmart Supercenters in the United States is directly related to an increase in body-mass index and obesity and show that for every additional Supercenter per 100,000 residents there is an increase in average body-mass index of 0.24 units and an increase in the obesity rate of 2.3 percentage points. In fact, these authors show that the proliferation of Walmart Supercenters explains 10.5 percent of the rise in obesity since the late 1980s in the United States. ${ }^{4}$

Related to the above, there are some clear indications that multinational corporations have invested heavily in local fast food industries with the aim to compensate for market share losses in developed countries as a result of strong public health campaigns against certain foods and

\footnotetext{
${ }^{4}$ Along these same lines, Blouin, et al. (2009), Offer, Pecher, et al. (2010), Ritzer and Malone (2000) also argue that another major factor in promoting poorer quality foods is the rapid growth of fast food chains and big retailers, leading to changes in taste and possibly obesity. Among others, relevant literature that explains the role of improved logistics, technology, and price reduction on obesity rates for the United States is Courtemanche, et al. (2016); Philipson and Posner (2003); Cutler, et al., (2003).
} 
drinks, in particular, those with high fat content and sugar (Costa-Font and Mas, 2016). Specifically, an important mechanism by which trade openness may impact obesity rates appears to be increased sugar consumption. It has been argued that open trade policies lower tariff barriers to imports of sugar-sweetened beverages, which may be linked to both obesity and related diseases in domestic societies (Lopez et al., 2017). In addition, low cost and wide availability of imported foods with both high fat and high sugar content result in consumption of cheaper, nutrient-poor foods rather than healthier alternatives (Cassels, 2016). Unlike traditional diets that tend to contain relatively more fresh fruits and vegetables, people around the world appear to be increasingly consuming diets that are high in fat and high in sugar and fructose, which resemble diets that are typical from western countries and in particular the United States (Hawkes et al., 2010; Popkin and Mendez 2007). Thus, the passing of free trade agreements may have further reduced the prices of refined sugar and other processed foods, which is compounded with the fact that they are convenient and have long shelf lives. These make them a particularly attractive choice to the poorer segments of the population in developing countries, as they tend to have difficulties with both conservation of fresh foods and access to clean, economical water to the point that it is not unheard of that sodas are sometimes considered an alternative to drinking water. ${ }^{5}$ Clearly, this may have contributed to a change in diets leading to obesity. Some recent empirical evidence appears to support this view. For instance, Barlow et al. (2017) find that tariff reductions brought by the North American Free Trade Agreement (NAFTA) coincide with a 41.6 kilocalorie per capita daily increase in the supply of caloric sweeteners in Canada. In fact, these authors claim that even a seemingly modest change to product tariffs in free trade agreements may substantially alter population-wide dietary behavior and exposure to risk factors. Thow and Hawkes (2009) consider

\footnotetext{
${ }^{5}$ See for instance: https://www.nytimes.com/2018/07/14/world/americas/mexico-coca-cola-diabetes.html.
} 
the impact of regional trade liberalization in Central America and argue that the policies of trade liberalization in the region over the past two decades, particularly in relation to the United States, have contributed to a 'nutrition transition' that is associated with rising rates of obesity and chronic diseases. Similarly, Siegel (2016) claims that as a result of NAFTA, foreign direct investment in the processed food industry surged, which is correlated with the tripling of consumption of sugary beverages between 1993 and 2014, and these are often cited as important contributors in making Mexico the most obese country in the world. In fact, Friel et al. (2013), Hawkes (2006), Zahra et al. (2015) among others explain that if potential impacts on nutrition and obesity risk are not taken into account and adjustments made accordingly, the proliferation of preferential trade and investment agreements may exacerbate the global burden of obesity-related chronic diseases, including diabetes, heart failure, and others. Interestingly, Milijovick et al. (2015) argue that while trade openness may be positively related to obesity, foreign direct investment shows little correlation to global obesity. These authors argue that openness and foreign direct investment adversely impact obesity in less developed countries, but have no link on obesity rates in developed ones. ${ }^{6}$ It has also been argued that foreign direct investment, which is greatly facilitated by free trade agreements, may be an important conduit in shaping the global market for highly processed foods and refined sugars. De Soysa and de Soysa (2018) argue that economic globalization, trade openness, foreign direct investment and economic freedom, appear to be negatively correlated with weight gain and obesity among children and youth. These researchers suggest that local-level factors explain the obesity patterns much more than global factors. They support the proposition

\footnotetext{
${ }^{6}$ Courtemanche et al. (2016) provide conflicting evidence that relates obesity rates to local economic conditions in the United States. They find that after controlling for demographic characteristics and state and year fixed effects, changes in several economic variables collectively explain 43 percent of the rise in obesity and 59 percent of the rise in obesity. Their analysis points to large effects among the heaviest individuals, with half the rise in the 90th percentile of the body-mass index explained by economic factors.
} 
that more globalized countries prioritize health in societies because of the importance of labor productivity and human capital due to heightened market competition.

As mentioned above, there is also a social dimension that may link free trade and obesity. Recent research argues for psychology-related effects of trade openness on obesity in particular, through invoking sentiments of inequality and relative deprivation. Individuals who possess particular sensibility to sentiments and perceptions related to inequality and relative deprivation may become demoralized, which may contribute to the adoption of undesirable eating habits and, in particular, overeating (e.g., Kawachi and Kennedy, 2002; Offer et al., 2010). In these so-called “obesogenic" environments, obesity rates may end up increasing (Wilkinson and Pickett, 2009). In addition, political scientists suggest that trade agreements may contribute to consumption of highly processed food by restraining governments from acting in the best interest of their populations (Blouin et al., 2009; Labonté and Sanger, 2006; McGrady, 2011). Furthermore, international openness may be contributing to the exporting of U.S. popular culture mainly through films, television, social media and advertising to countries that previously were more isolated, thus helping shift cultural paradigms and incentivizing specific fads, which may contribute to the increase in obesity rates and thus, obesity-related illnesses (Siegel, 2016).

\section{Data and Methodology}

While several of the studies mentioned above argue for the existence of a causal link between trade openness and obesity rates, the empirical approaches applied by most, if not all, of the existing studies are unconvincing. In this research, we exploit spatial and time variation in trade agreements with the United States to estimate the effect of free trade agreements (FTAs) on obesity. For the empirical analysis, we focus on the period 1990-2016 and employ data at the 
country level from three publicly available sources, the World Trade Organization (WTO), the World Bank, and the World Health Organization (WHO). From the WTO, we obtain information on the year in which countries signed a FTA with the United States within our sample period of interest. ${ }^{7}$ In particular, we construct a dichotomous variable that takes the value of one for those years in which the country maintained a FTA with the United States or assign a zero otherwise. We observe that 19 countries signed their trade agreements in the last two decades excluding Israel. ${ }^{8}$ Our obesity indicator is from the WHO-Global Health Observatory Database, indicating the prevalence of obesity among adults. ${ }^{9}$ According to WHO, this variable is defined as the percentage of the adult population aged 18 and over with a Body Mass Index (BMI) of $30 \mathrm{~kg} / \mathrm{m}^{2}$ or higher. This index is calculated as the weight in kilograms divided by the height in square meters, and it is commonly used to classify adults as underweighted (BMI < 18.5), overweight $(\mathrm{BMI} \geq 25)$, and obese $(\mathrm{BMI} \geq 30)$. We use the age-standardized estimate of the obesity rate under the WHO World Standard. This method consists of a weight-balance of the age structure of a standard population, which allows the prevalence of obesity to be comparable among countries despite their differences in age distribution. We include a set of demographic, social, and economic covariates at the country level that may potentially impact obesity prevalence and be correlated with free trade agreements. In particular, we control for different age ranges as a percentage of total population, including the following ranges, 0-14 years old, 15-64 years old and 65 years old and older. These variables respond to the variability in age structure by country that could skew the comparison of obesity prevalence between countries. We also include overall economic

\footnotetext{
${ }^{7}$ Our preferred period is 1990 to 2016, as most Free Trade Agreements with the United States were enacted in 1990 or later. The only exception is Israel, country that enacted a trade agreement with the United States in 1985.

${ }^{8}$ Appendix 1 provides the list of countries that signed a free trade agreement with the United States during the period 1990 to 2016, 20 countries in total.

${ }^{9}$ Available at: https://www.who.int/gho/en/.
} 
indicators that are standard in empirical macroeconomic empirical work, such as the rate of growth in Gross Domestic Product (GDP), the logarithm of the GDP per capita, trade prevalence as a percentage of GDP, net migration, and school enrollment on secondary levels. ${ }^{10}$ All the covariates employed in this research come from the World Development Indicators from the World Bank website. ${ }^{11}$ Summary statistics are presented in Table $1 .{ }^{12}$

Table 1. Descriptive Statistics, 1990-2016

\begin{tabular}{lrrr}
\hline \hline Covariates & N. Obs. & Mean & Std. \\
GDP growth (annual percent) & & & \\
Log GDP per capita (\$2010) & 3,187 & 3.581 & 6.030 \\
Net migration (thousands) & 3,183 & 8.495 & 1.521 \\
Population ages 0-14 (percent of total) & 3,213 & 6.771 & 746.523 \\
Population ages 15-64 (percent of total) & 3,209 & 30.146 & 10.684 \\
Enrollment secondary school & 3,209 & 61.930 & 6.600 \\
Female population & 3,267 & 74.815 & 31.405 \\
Food Industry (share of GDP) & 3,183 & 0.503 & 0.021 \\
Rural population (percent of total) & 3,267 & 0.246 & 0.431 \\
Outcome Variable & 3,260 & 0.439 & 0.229 \\
Obesity rate (percent BMI>=30) & & & \\
& 3,267 & 14.625 & 8.843 \\
\hline \hline
\end{tabular}

Methodologically, we exploit spatial and time variation in the trade agreements using a difference-in-differences approach in order to test for any causal impact from grade to obesity. Simply put, we compare the percentage of obese populations between countries engaged in free trade agreements and countries that have not engaged in free trade agreements with the United States during our sample period, before and after the change in trade agreements. In particular, we

\footnotetext{
${ }^{10}$ Our results are robust to changes in specification when following formal empirical tests such as Sala-i-Martin (1997). These findings are available upon request.

${ }^{11} \mathrm{http} / / /$ datatopics.worldbank.org/world-development-indicators/.

${ }^{12}$ Interestingly, the data show that approximately 14.3 percent of the total population is obese and that obesity in women is 6.6 percentage points higher than in men. Also, these descriptive data indicate that the annual consumption of sugar reaches up to 23.9 kilograms per capita.
} 
estimate the following specification:

$$
y_{c t}=\beta_{0}+\beta_{1} T L C_{c t}+\mathbf{X}_{c t} \boldsymbol{\beta}_{2}+\gamma_{c}+\delta_{t}+\eta_{c t}
$$

where $y_{c t}$ denotes the percentage of population with BMI at 30 or higher in country $c$ in year $t$; TLC is an indicator for whether country $c$ open to free trade with the United States in year $t$; and $\mathbf{X}_{c t}$ is a full vector of country-level covariates. The remaining terms, $\gamma_{c}$ and $\delta_{t}$, represent country and year fixed effects. Conditional on observable characteristics, and using fixed effects to eliminate the influence of unobservable characteristics, countries will be different in obese population only, given the differences in the enactments of free trade agreements with the United States. We also test the robustness of our specification by adding a continent-specific linear time trend to control for differential trends in obesity that might be correlated with the timing of opening to free trade. Standard errors are clustered at the country level, allowing for within-country serial correlation in the errors terms while assuming these are independent across countries because unobserved factors may be correlated over time (Bertrand et al., 2004).

The coefficient of interest $\beta_{1}$ represents the estimated effect on obesity rates. The identification relies on the assumption that trends in the outcome variable in countries in the control group are a reasonable counterfactual. That is, trends in the percentage of obese population in treatment countries would have been the same as in the control countries in the absence of the treatment. In order to investigate this issue, namely that there are no differential trends between treatment and control countries, we estimate the following empirical specification:

$$
y_{c t}=\beta_{0}+\sum_{i=-6}^{6} \theta_{i} 1\left(\tau_{c t}=i\right)+\mathbf{X}_{c t} \boldsymbol{\beta}_{2}+\gamma_{c}+\delta_{t}+\eta_{c t}(2)
$$

where $\tau_{c t}$ indicates the event year, defined so that case $\tau=0$ denotes the year of the policy change, $\tau=1$ is the year after the policy change, and so on. For $\tau \leq-1$, countries were untreated, 
i.e., before they engage in free trade with the United States. The coefficients $\theta$ are estimated relative to one year before the policy change $(\tau=-1)$, the omitted coefficient. Note that $i$ equal to -6 or 6 denotes more than five years before or after, respectively, opening to free trade.

In addition, we investigated heterogeneities at the country level and, in particular, we consider the degree of country development, which is captured by considering OECD and nonOECD countries, countries with larger rural/urban population, gender differences, and countries with younger/older population. Finally, we also consider a set of robustness tests first by applying synthetic control methods. Second, running a placebo test with random dates and third, by mechanically maximizing our sample.

\section{Main Findings}

Table 2 shows our results when applying the empirical specification described in (1). Overall, we find that signing a free trade agreement with the United States increases the percentage of the obese population in treated countries. The first column shows findings controlling for all covariates listed in Table 1, GDP growth, log of per capita GDP, percentage of population of age 0-14 and 15-64, enrollment in secondary school, and net migration—including fixed effects at the country level, which help remove the effect of unobservable country-specific characteristics. We find that the percentage of obese population increases by approximately 9.8 percentage points over the sample mean. The second column shows results when including continent-specific time trends to control for macro-regional factors, e.g., climatic factors, which may be correlated with regional socio-economic status or development. In this case, the coefficient of our variable of interest remains statistically significant although the magnitude substantially decreases. In column three, we include the interactions of the covariates, which allows us to control for interaction effects in important country time-varying characteristics. Including this additional flexibility in the model 
seems to capture unobserved heterogeneity and the reduction of health effects of free trade with the United States. The last column finally includes both factors, covariates interactions and continent-specific trends. Using this flexible specification, we find that the causal impact of free trade agreements on obesity is about 4.4 percentage point over the sample mean for obesity rate.

\section{Table 2. Free Trade Agreements on Obesity Rates, 1990-2016}

\section{Main Results}

Free trade $=1$

Country and year fixed effects

Covariates interactions

Continent-specific trend

Observations

R-squared

Mean obesity

Notes: To be classified as obese the BMI should be greater or equal than $30 \mathrm{~kg} / \mathrm{m}^{2}$. Each regression controls for covariates such as GDP growth, log of per capita GDP, percentage of population of age 0-14 and 15-64,

enrollment in secondary school, and net migration. Standard errors are clustered at the country level.
(1)

$1.391 * * *$

(0.370)

Yes

No

No

$\begin{array}{lrr}3,098 & 3,098 & 3,098 \\ 0.8906 & 0.9237 & 0.9158 \\ 14.26 & & \\ \text { equal than } 30 \mathrm{~kg} / \mathrm{m}^{2} . \text { Each regression control } \\ \text { ge of population of age } 0-14 \text { and } 15-64, \\ \text { ors are clustered at the country level. }\end{array}$

(4)

$0.625^{*}$

$(0.343)$

$(0.348)$

Yes Yes

Yes Yes

Yes

3,098

0.9236

As it is well known, a necessary condition to make a causal interpretation of the findings above relies on the presumption that there should be no pre-existing trend differences in obesity rates between treatment and control groups. Finding this implies that countries are observationally similar in the pre-treatment period and presumably would have remained so had they not open to free trade with the United States. Figure 1 shows our results when applying the empirical specification in (2) above. We find that there is generally rather convincing evidence for the lack of trend differences in obesity in the years prior to the change in trade policy. Indeed, trends in the pre-treatment period are remarkably flat and indistinguishable from zero. This confirms the idea that the counterfactual trend behaviors of treatment and control groups are statistically the same and support the causal interpretation of the treatment effect (Angrist and Pischke, 2008). Furthermore, Figure 1 shows a sustained increase in the rate of obese population in the period 
following the policy change. After an initial slightly increasing trend in the first three years after trade agreements with the United States were enacted, we find that this positive trend increases at a much higher rate in subsequent years.

Figure 1. Event Study: Free Trade with the United States on Obesity Rate, 1990-2016

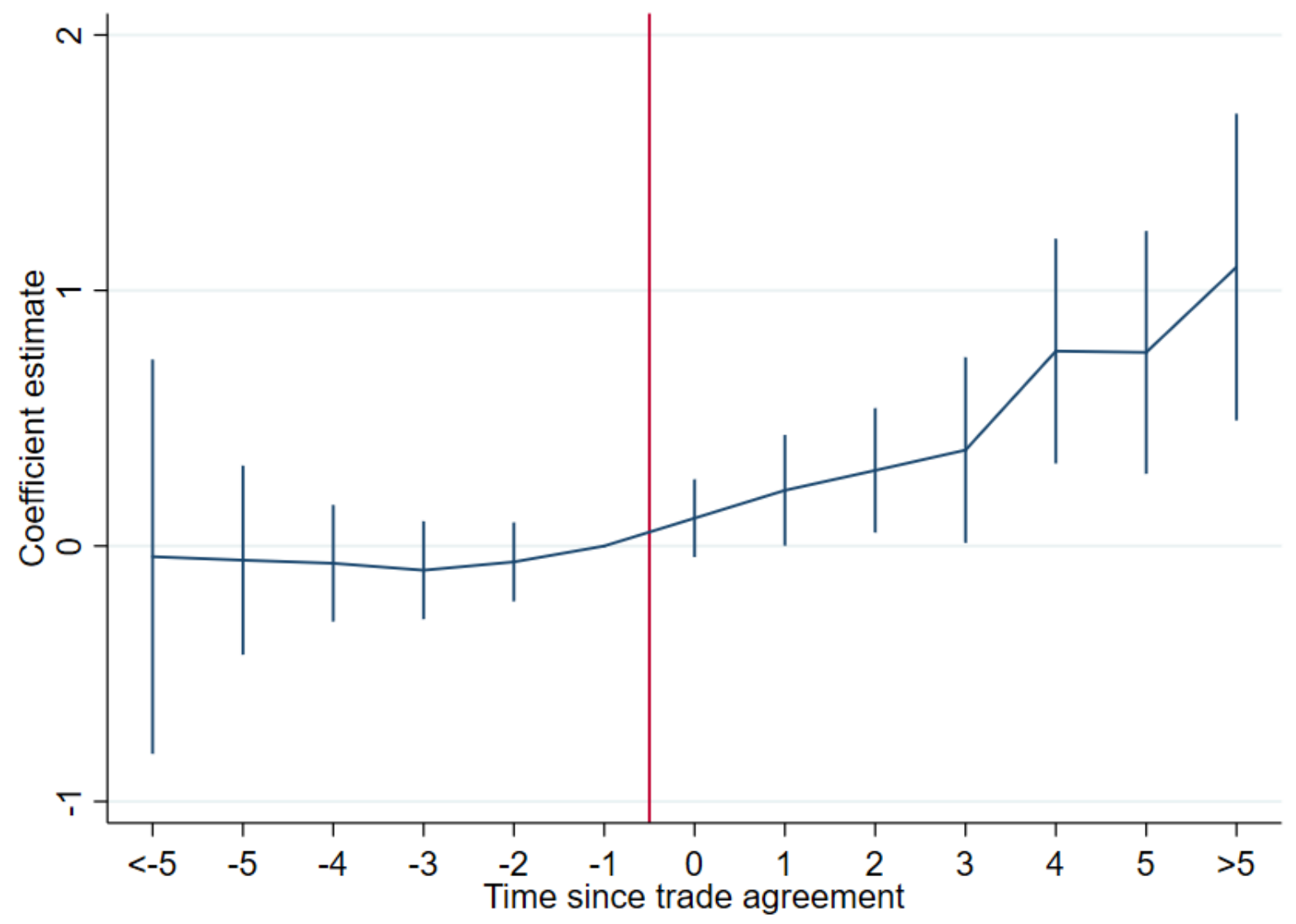

Notes: The graph show parameter estimates for the years before and after the change in free trade agreement from a regression that controls for country and year fixed effects as well as GDP growth, log of per capita GDP, percentage of population of age 0-14 and 15-64, enrollment in secondary school, and net migration, interaction between covariates and continent-specific time trends. Standard errors are clustered at the country level. Year -1 is the reference event and its coefficient is not estimated and thus equal to zero.

In Table 3, we investigate some basic heterogeneities in the effect of trade liberalization across different characteristics. In particular, we distinguish the treatment by whether a country belongs to OECD by interacting the treatment variable indicating whether a country open to free trade with the United States, $T L C$ from equation (1), with a dummy variable taking a value equal to 1 when the country is in the OECD, 0 otherwise, and with one taking value 1 if not in the OECD 
and 0 otherwise. Results indicate that the estimated increase is also larger for OECD countries, 5.1 percentage points, than non-OECD countries, 4.2 percent over the sample mean, although this is not statistically significant.

We proceed to investigate how the effect varies across two demographic dimensions. First, we examine whether trade liberalization has a different effect for younger and older populations. There is a reason to expect that young individuals would show higher increase in obesity rate because they are more likely to eat at fast food restaurants. To investigate this, we estimate the interaction between the treatment variable and a dummy variable that equals 1 when the country is above/below the $50^{\text {th }}$ percentiles for share of population of age $0-14$; 0 otherwise. Our results suggest that countries with a largest share of young population experience a larger increase in obesity rate, 7.1 versus 3.2 percentage points. Finally, we investigate countries that are more urbanized and thus have greater access to fast food restaurants. To do this, we interact the treatment variable with a dummy variable that equals 1 when the country is above/below the $50^{\text {th }}$ percentiles for share of population living in rural areas; 0 otherwise. Results suggest that, as expected, countries with more urbanized areas experience a larger increase in obesity rate.

Finally, we focus on whether gender matters by using the share of female population and define this category as being above or below the median. We find that the median is very close to 0.5, which means that while the variable is statistically significant at conventional levels, economically speaking the impact is not really different with respect to males. 
Table 3. Basic Heterogeneities

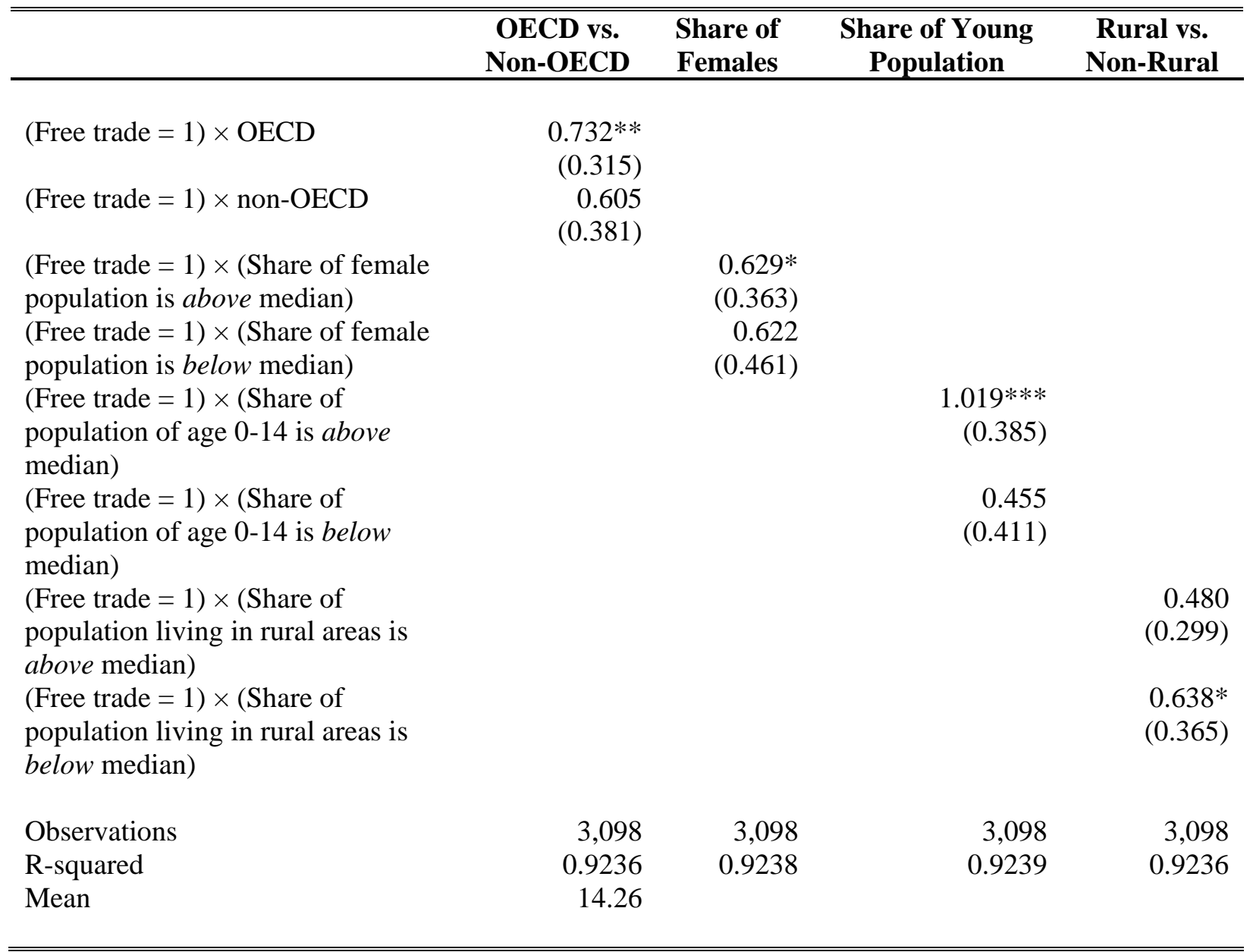

Notes: The dependent variable is obesity rates. To be classified as obese the BMI should be greater or equal than $30 \mathrm{~kg} / \mathrm{m}^{2}$. Each regression controls for country and year fixed effects, continent-specific time trends, as well as GDP growth, $\log$ of per capita GDP, percentage of population of age 0-14 and 15-64, enrollment in secondary school, and net migration, and their interactions. OECD vs. Non-OECD symbolizes a regression where the treatment variable is interacted with a dummy variable denoting OECD status, i.e., taking value equal to 1 if the country is, or is not, part of OECD; 0 otherwise. Share of Female Population is a regression where the treatment variable is interacted with a dummy variable that equals 1 when the country is above/below the $50^{\text {th }}$ for share of female population; 0 otherwise. Share of Young Population is a regression where the treatment variable is interacted with a dummy variable that equals 1 when the country is above/below the $50^{\text {th }}$ percentiles for share of population of age $0-14 ; 0$ otherwise. Rural vs. Non-Rural is a regression where the treatment variable is interacted with a dummy variable that equals 1 when the country is above/below the $50^{\text {th }}$ percentiles for share of population living in rural areas; 0 otherwise. Each regression controls for country and year fixed effects all covariates listed in Table 1. Standard errors are clustered at the country level. Testing the linear hypotheses of equality of each pair of parameters with a Wald test obtained for non-clustered standard errors. Clustering at continent or country level, we cannot reject the hypothesis that coefficients are statistically equal. 


\section{Robustness}

As a robustness method, we apply placebo tests to help us confirm whether or not our findings are not spurious. We do this by replacing the main policy variable with 1,000 sets of placebo dates for the change in free trade agreements for the treated countries in our sample. Using a uniform distribution, we randomly generated 1,000 sets of fake dates from 1991 to one year before the actual effective date of the change in the trade agreement. To avoid contaminating the test with the truly treated data, we drop observations from the true treated period. Then, we estimate equation (1) one thousand times where at each time we define the treatment indicator according to the placebo dates. We find that these placebo dates do not capture any effect for the fake changes in trade agreements change. This is shown in Table 4. The estimated effects are small and positive (0.108), and statistically insignificant at most conventional levels (standard error 0.135). They were positive and statistically significant at 5- and 10-percent levels only, seven and 33 times out of 1,000 replications, respectively.

\section{Table 4. Placebo Dates for Free Trade Agreements}

\begin{tabular}{lr}
\hline \hline Average placebo estimate & 0.108 \\
& $(0.135)$ \\
Placebo coefficient $>0$ & 777 \\
Placebo coefficient $>0$ and significant at 5 percent level & 7 \\
Placebo coefficient $>0$ and significant at 10 percent level & 33 \\
Number of observations & 2,946 \\
\hline Notes: $* * *$ p $<0.01, * *$ p $<0.05, *$ p $<0.1$. The dependent variable is obesity rates. The effect of \\
trade liberalization was estimated for placebo (fake) dates, i.e., assigning random dates of the \\
effectiveness of the policy to liberalizing countries with 1000 trials. Each regression controls for \\
country and year fixed effects, continent-specific time trends, as well as GDP growth, log of per \\
capita GDP, percentage of population of age 0-14 and 15-64, enrollment in secondary school, \\
and net migration, and their interactions. Standard errors are clustered at the country level.
\end{tabular}

For the sake of completeness we also re-estimate our differences-in-differences method shown in (1) for a sample that goes from 1980 to 2016, which maximizes all the available data. As mentioned above, this sample size is not considered as our preferred one, as all the Free Trade 
Agreements enacted with the United States occurred in the 1990s or later, with the exception of Israel, which was enacted in the mid-1980s. As shown in Appendix 2, we find statistically significant results that are even stronger than when using our preferred sample size. ${ }^{13}$ In addition, when using this expanded sample size the economic magnitudes are also larger. ${ }^{14}$

In order to further test the robustness of our findings, we apply synthetic control methods instead of using our preferred differences-in-differences approach. As in the previous case, we test for equal trends by generating a synthetic counterfactual for each country that enacted free trade agreements with the United States during the period 1990-2016, as shown in Appendix 3. To do this, we take a linear combination of the outcome variable from the pool of countries that did not change the trade agreements during the sample period. As it is well known, this method minimizes the pre-treatment trend difference between the treated and the synthetic country, thus generating a better counterfactual for the treatment country (Abadie and Gardeazabal, 2003; Abadie et al., 2010). We estimate the same synthetic control design for each treated country using data on the outcome variable in the pre-treatment period. Then, we pool the data for each treated group and its synthetic control to generate a sample that we use to investigate the robustness of the estimated effect to the choice of counterfactuals. The causal interpretation of the results is further confirmed by the event study obtained by estimating equation (2) using the data pooled from the synthetic control analysis in Appendix 2. Similarly, when re-estimating (1) using the pooled data we also find that following the change in policy, the percentage of obese population rapidly increases as compared to the synthetic counties and that this finding is statistically significant at conventional

\footnotetext{
${ }^{13}$ In particular, observe Column 2 and Column 4, which are now statistically significant at 1 percent and 5 percent, respectively.

${ }^{14}$ Event studies along the lines of (2) were also performed. We find very similar results to the ones presented in Figure 1. These results are available upon request.
} 
levels. These findings are shown in Appendix 4. Admittedly, when using synthetic control methods, the economic impact of trade on obesity liberalization-while still economically significant—appears to be smaller relative to the sample mean when compared with respect to our preferred differences-in-differences approach. A reason for this may be the relatively large reduction in sample size when using synthetic controls. Still, in light of all the empirical evidence presented and the robustness tests performed, we are confident that statistically and economically significant causal impacts are present between free trade and obesity rates. While the empirical evidence regarding the range of economic impact presented in this paper appears to be broad, additional future research should help obtain more precise ranges. ${ }^{15}$

\section{One Possible Underlying Mechanism}

As suggested in recent media coverage and related literature briefly described above, in this section we focus on one potentially critical underlying mechanism that may be contributing to driving obesity rates up, namely, sugar consumption. We explore whether enacting free trade agreements with the United States may increase access to food and beverage products that tend to be associated with higher sugar content, thus fostering overall sugar consumption and contributing to increased obesity rates. In order to do this, we estimate the same specification (1) but employ the annual per-capital sugar consumption as the dependent variable instead. Table 5 shows our results. We find that per-capita consumption of sugar increased because of free trade with the States, as the corresponding coefficient is positive and statistically significant at conventional levels. In our preferred specification, in column 4, which includes country fixed effects and is clustered at the country level, we find that the causal impact of free trade agreements on sugar

\footnotetext{
${ }^{15}$ A specific method to consider is based on recent research by Arkhangelsky et al. (2019), who propose an approach that combines synthetic methods with differences-in-differences.
} 
consumptions is about 8.2 percent. $^{16}$

Table 5. Free Trade Agreements and Sugar Per-capita Consumption, 1990-2016

\begin{tabular}{|c|c|c|c|c|}
\hline & $(1)$ & $(2)$ & (3) & (4) \\
\hline Free trade $=1$ & $\begin{array}{r}6.765 * * * \\
(0.820)\end{array}$ & $\begin{array}{r}6.765 * * * \\
(2.187)\end{array}$ & $\begin{array}{r}1.958 * * * \\
(0.484)\end{array}$ & $\begin{array}{r}1.958 * * \\
(0.879)\end{array}$ \\
\hline GDP growth (annual percent) & $\begin{array}{r}-0.0733 \\
(0.0481)\end{array}$ & $\begin{array}{l}-0.0733 \\
(0.0693)\end{array}$ & $\begin{array}{l}0.0413 * \\
(0.0219)\end{array}$ & $\begin{array}{l}0.0413^{*} \\
(0.0239)\end{array}$ \\
\hline Log GDP per capita & $\begin{array}{r}0.0709 \\
(0.388)\end{array}$ & $\begin{array}{r}0.0709 \\
(1.302)\end{array}$ & $\begin{array}{r}0.441 \\
(0.922)\end{array}$ & $\begin{array}{r}0.441 \\
(1.822)\end{array}$ \\
\hline Public health expenditure & $\begin{array}{r}1.274 * * * \\
(0.190)\end{array}$ & $\begin{array}{l}1.274^{*} \\
(0.661)\end{array}$ & $\begin{array}{l}-0.158 \\
(0.130)\end{array}$ & $\begin{array}{l}-0.158 \\
(0.343)\end{array}$ \\
\hline Trade (percent of GDP) & $\begin{array}{r}0.00658 \\
(0.00819)\end{array}$ & $\begin{array}{l}0.00658 \\
(0.0300)\end{array}$ & $\begin{array}{l}-0.00678 \\
(0.00665)\end{array}$ & $\begin{array}{r}-0.00678 \\
(0.0192)\end{array}$ \\
\hline Unemployment (percent of total & & & & \\
\hline labor) & $\begin{array}{r}-0.0444 \\
(0.0386)\end{array}$ & $\begin{array}{r}-0.0444 \\
(0.118)\end{array}$ & $\begin{array}{l}-0.0655^{*} \\
(0.0372)\end{array}$ & $\begin{array}{r}-0.0655 \\
(0.0629)\end{array}$ \\
\hline Life expectancy at birth (years) & $\begin{array}{r}0.0416 \\
(0.0683)\end{array}$ & $\begin{array}{r}0.0416 \\
(0.215)\end{array}$ & $\begin{array}{r}-0.0112 \\
(0.103)\end{array}$ & $\begin{array}{r}-0.0112 \\
(0.168)\end{array}$ \\
\hline Population ages $0-14$ percent of total) & $\begin{array}{r}0.599 * * * \\
(0.0925)\end{array}$ & $\begin{array}{r}0.599 * * \\
(0.296)\end{array}$ & $\begin{array}{r}-1.451 * * * \\
(0.171)\end{array}$ & $\begin{array}{r}-1.451 * * * \\
(0.480)\end{array}$ \\
\hline $\begin{array}{l}\text { Population ages } 15-64 \text { percent of } \\
\text { total) }\end{array}$ & $\begin{array}{r}0.222 \\
(0.159)\end{array}$ & $\begin{array}{r}0.222 \\
(0.523)\end{array}$ & $\begin{array}{r}-1.018 * * * \\
(0.164)\end{array}$ & $\begin{array}{r}-1.018 * * \\
(0.400)\end{array}$ \\
\hline Infant mortality rate & $\begin{array}{r}-0.199 * * * \\
(0.0312)\end{array}$ & $\begin{array}{r}-0.199 * * \\
(0.0941)\end{array}$ & $\begin{array}{r}-0.148 * * * \\
(0.0235)\end{array}$ & $\begin{array}{r}-0.148 * * * \\
(0.0547)\end{array}$ \\
\hline Population growth (annual percent) & $\begin{array}{r}-0.435 \\
(0.342)\end{array}$ & $\begin{array}{l}-0.435 \\
(0.862)\end{array}$ & $\begin{array}{r}0.503 * * * \\
(0.174)\end{array}$ & $\begin{array}{r}0.503 \\
(0.352)\end{array}$ \\
\hline School enrollment primary & $\begin{array}{r}-0.0538 * * * \\
(0.0175)\end{array}$ & $\begin{array}{r}-0.0538 \\
(0.0414)\end{array}$ & $\begin{array}{r}0.0206 \\
(0.0146)\end{array}$ & $\begin{array}{r}0.0206 \\
(0.0237)\end{array}$ \\
\hline School enrollment secondary & $\begin{array}{r}0.0657 * * * \\
(0.0177)\end{array}$ & $\begin{array}{r}0.0657 \\
(0.0551)\end{array}$ & $\begin{array}{r}0.00759 \\
(0.0121)\end{array}$ & $\begin{array}{r}0.00759 \\
(0.0200)\end{array}$ \\
\hline Fertility rate & $\begin{array}{r}-1.952 * * \\
(0.767)\end{array}$ & $\begin{array}{l}-1.952 \\
(2.148)\end{array}$ & $\begin{array}{r}-0.436 \\
(0.536)\end{array}$ & $\begin{array}{r}-0.436 \\
(1.266)\end{array}$ \\
\hline Corruption & $\begin{array}{r}-0.291 \\
(0.238)\end{array}$ & $\begin{array}{r}-0.291 \\
(0.717)\end{array}$ & $\begin{array}{r}0.303 * * \\
(0.153)\end{array}$ & $\begin{array}{r}0.303 \\
(0.307)\end{array}$ \\
\hline Net migration & $\begin{array}{r}0.00146 * * * \\
(0.000416)\end{array}$ & $\begin{array}{r}0.00146 \\
(0.00126)\end{array}$ & $\begin{array}{r}-0.000211 \\
(0.000275)\end{array}$ & $\begin{array}{r}-0.000211 \\
(0.000446)\end{array}$ \\
\hline $\begin{array}{l}\text { Observations } \\
\text { R-squared }\end{array}$ & $\begin{array}{r}1,650 \\
0.4889\end{array}$ & $\begin{array}{r}1,650 \\
0.4889\end{array}$ & $\begin{array}{r}1,650 \\
0.1556\end{array}$ & $\begin{array}{r}1,650 \\
0.1556\end{array}$ \\
\hline
\end{tabular}

${ }^{16}$ Appendix 5 shows the related event study graph that tests for pre-existing trends between free trade agreements and sugar consumption when using equation (2) shown in the text. Our results show a dip down in consumption two years before the policy change and that sugar consumption trends are essentially not different from zero. In fact, we find a dramatic increase in sugar consumption during the first two years after trade agreements were enacted followed by a somewhat stable period in the latter part of our sample period. Overall, these findings are fully consistent with the assumption of equal trends. 
Mean sugar consumption

Country fixed effects

Clustering by country
23.87

\begin{tabular}{llll} 
No & No & Yes & Yes \\
No & Yes & No & Yes \\
\hline
\end{tabular}

Notes: $* * * \mathrm{p}<0.01, * * \mathrm{p}<0.05, * \mathrm{p}<0.1$. Standard errors are clustered at the country level.

\section{Conclusions}

By using a differences-in-differences approach that exploits time and geographic variation in free trade agreements with the United States, we provide causal evidence that such agreements may cause an increase in obesity rates in countries that signed them during the period 1990 and 2016. Our findings are supported by extensive robustness checks that include the use of event studies, synthetic control methods, changes in sample size, and placebo tests. We find that our findings are consistent with recent claims that blame free trade with a rather dramatic increase in obesity rates in both developed and developing countries to the point that some media commentators and some authors have already coined a specific term for this phenomenon namely “Globesity" (Delpeuch et al., 2009).

We hope that our future research will help us better understand the role of the specific mechanisms that appears to be driving our findings. Among others, this is the case of foreign direct investment of multinational fast-food chains in developing countries, the role of sugar in the increase in obesity rates in the world, and the role of fads and social media in exacerbating obesity and other health-related phenomena across countries. In addition, our future research aims at achieving a better understanding of whether potential health decline due to obesity-related illnesses disproportionately fall on people of lesser means, as extensive anecdotal evidence appears to show. ${ }^{17}$ Finally, it might be time for policymakers to become more aware that, as a result of trade

\footnotetext{
${ }^{17}$ Please, see Footnote 2.
} 
openness, an unintended consequence may be a trade-off between economic performance and health quality in societies. 


\section{References}

Abadie, A., and Gardeazabal, J. (2003), "The Economic Costs of Conflict: A Case Study of the Basque Country," American Economic Review, 93 (1), 112-132.

Abadie, A., Diamond, A. and Hainmueller, J., (2010). Synthetic control methods for comparative case studies: Estimating the effect of California's tobacco control program. Journal of the American Statistical Association, 105(490), pp.493-505.

Arkhangelsky, D., Athey, S., Hirshberg, D.A., Imbens, G.W. and Wager, S., 2019. Synthetic difference in differences (No. w25532). National Bureau of Economic Research.

Barlow, P., McKee, M., Basu, S., \& Stuckler, D. (2017). Impact of the North American Free Trade Agreement on high-fructose corn syrup supply in Canada: a natural experiment using synthetic control methods. Canadian Medical Association Journal, 189(26), E881-E887.

Blouin, C., Chopra, M., \& van der Hoeven, R. (2009). Trade and social determinants of health. The Lancet, 373(9662), 502-507.

Cassels, S. (2006). Overweight in the Pacific: links between foreign dependence, global food trade, and obesity in the Federated States of Micronesia. Globalization and Health, 2(1), 10.

Costa-Font, J., \& Mas, N. (2016). 'Globesity'? The effects of globalization on obesity and caloric intake. Food Policy, 64, 121-132.

Courtemanche, Charles and Art Carden (2011) "Supersizing supercenters? The impact of Walmart Supercenters on body mass index and obesity", Journal of Urban Economics, 69, 2: 165181

Courtemanche, Charles, Josh Pinkston, Chris Ruhm, and George Wehby (2016). "Can Changing Economic Factors Explain the Rise in Obesity?" Southern Economic Journal, 82(4): 12661310.

D. Cutler, E. Glaeser, J. Shapiro (2003) “Why Have Americans Become More Obese?”, Journal of Economic Perspectives, 17: 93-118

de Soysa, I., \& de Soysa, A. K. (2018). Do Globalization and Free Markets Drive Obesity among Children and Youth? An Empirical Analysis, 1990-2013. International Interactions, 44(1), 88-106.

Delpeuch, F., Maire, B., Monnier, E., Holdsworth, M. (2009). Globesity: A planet out of control? Earthscan: London, U.K 
Friel, S., Hattersley, L., Snowdon, W., Thow, A. M., Lobstein, T., Sanders, D., ... \& Kumanyika, S. (2013). Monitoring the impacts of trade agreements on food environments. Obesity Reviews, 14(S1), 120-134.

Goryakin, Y., Lobstein, T., James, W. P. T., \& Suhrcke, M. (2015). The impact of economic, political and social globalization on overweight and obesity in the 56 low and middle income countries. Social Science \& Medicine, 133, 67-76.

Hawkes, C. (2006). Uneven dietary development: linking the policies and processes of globalization with the nutrition transition, obesity and diet-related chronic diseases. Globalization and health, 2(1), 4.

Hawkes, C. (2010). The influence of trade liberalisation and global dietary change: the case of vegetable oils, meat and highly processed foods. In Trade, food, diet and health: perspectives and policy options, Oxford: Blackwell, 35-59.

Hawkes, C., Blouin, C., Henson, S., Drager, N., \& Dubé, L. (2009). Trade, food, diet and health: perspectives and policy options. John Wiley \& Sons

Kawachi, I., \& Kennedy, B. P. (2002). The Health of Nations: Why Inequality is Harmful to your Health. NewYork: New Press

Labonte, R., \& Sanger, M. (2006). Glossary of the World Trade Organisation and public health: part 1. Journal of Epidemiology \& Community Health, 60(8), 655-661.

Lopez, A. M., Loopstra, R., McKee, M., \& Stuckler, D. (2017). Is trade liberalisation a vector for the spread of sugar-sweetened beverages? A cross-national longitudinal analysis of 44 lowand middle-income countries. Social Science \& Medicine, 172, 21-27.

McGrady, B. (2011). Trade and public health: The WTO, tobacco, alcohol, and diet. UK: Cambridge University Press.

Miljkovic, D., Shaik, S., Miranda, S., Barabanov, N., \& Liogier, A. (2015). Globalisation and obesity. The World Economy, 38(8), 1278-1294.

Ng, M., Fleming, T., Robinson, M., Thomson, B., Graetz, N., Margono, C., ... \& Abraham, J. P. (2014). Global, regional, and national prevalence of overweight and obesity in children and adults during 1980-2013: a systematic analysis for the Global Burden of Disease Study 2013. The Lancet, 384(9945), 766-781.

Offer, A., Pechey, R., \& Ulijaszek, S. (2010). Obesity under affluence varies by welfare regimes: the effect of fast food, insecurity, and inequality. Economics \& Human Biology, 8(3), 297- 
308.

Philipson, T. and R. Posner (2003) "The Long Run growth of Obesity as a Function of Technological Change" Perspectives in Biology and Medicine, 46: 7-108

Poobalan, A., \& Aucott, L. (2016). Obesity among young adults in developing countries: a systematic overview. Current Obesity Reports, 5(1), 2-13.

Popkin, B. M., \& Mendez, M. (2007). The rapid shifts in stages of the nutrition transition: The global obesity epidemic. Globalization and Health, 68-80.

Ritzer, G., \& Malone, E. L. (2000). Globalization theory: Lessons from the exportation of McDonaldization and the new means of consumption. American Studies, 41(2/3), 97-118.

Sala-i-Martin (1997) “I Just Run Two Million Regressions”, American Economic Review, Papers and Proceedings, 87, 2: 178-83.

Schrecker, T., \& Bambra, C. (2015). How Politics Makes us Sick: Neoliberal epidemics. U.K: Palgrave MacMillan.

Siegel, A. D. (2016). NAFTA Largely Responsible for the Obesity Epidemic in Mexico. Washington University Journal of Law and Policy, 50, 195.

Thow, A. M., \& Hawkes, C. (2009). The implications of trade liberalization for diet and health: a case study from Central America. Globalization and health, 5(1), 5.

Vandevijvere, S., Chow, C. C., Hall, K. D., Umali, E., \& Swinburn, B. A. (2015). Increased food energy supply as a major driver of the obesity epidemic: a global analysis. Bulletin of the World Health Organization, 93(7), 446-456.

Vogli, R. D., Kouvonen, A., Elovainio, M., \& Marmot, M. (2014). Economic globalization, inequality and body mass index: a cross-national analysis of 127 countries. Critical Public Health, 24(1), 7-21.

Wilkinson, R. G., \& Pickett, K. E. (2009). Income inequality and social dysfunction. Annual Review of Sociology, 35, 493-511.

Zahra, A., Lee, E. W., Sun, L. Y., \& Park, J. H. (2015). Cardiovascular disease and diabetes mortality, and their relation to socio-economical, environmental, and health behavioural factors in worldwide view. Public health, 129(4), 385-395. 
Appendix 1. Free Trade Agreements with the United States 1980-2016

\begin{tabular}{|c|c|}
\hline$\overline{\text { Country }}$ & Year \\
\hline Australia & 2004 \\
\hline Bahrain & 2006 \\
\hline Canada & 1994 \\
\hline Chile & 2004 \\
\hline Colombia & 2012 \\
\hline Costa Rica & 2005 \\
\hline Dominican Republic & 2005 \\
\hline El Salvador & 2005 \\
\hline Guatemala & 2005 \\
\hline Honduras & 2005 \\
\hline Israel & 1985 \\
\hline Jordan & 2001 \\
\hline Korea, Rep. & 2012 \\
\hline Mexico & 1994 \\
\hline Morocco & 2011 \\
\hline Nicaragua & 2005 \\
\hline Oman & 2006 \\
\hline Panama & 2012 \\
\hline Peru & 2007 \\
\hline Singapore & 2004 \\
\hline
\end{tabular}

Source: World Trade Organization 


\section{Main Results}

Free trade $=1$

Country and year fixed effects

Continent-specific trend

Covariates interactions

Observations

R-squared

Mean obesity

\section{Robustness}

Placebo Dates for FTAs

Average placebo estimate

(1)

(2)

(3)

(4)

$\begin{array}{rrrr}1.822 * * * & 1.308^{* * *} & 1.396 * * * & 0.946 * * \\ (0.428) & (0.446) & (0.413) & (0.397) \\ & & & \\ \text { Yes } & \text { Yes } & \text { Yes } & \text { Yes } \\ \text { No } & \text { No } & \text { Yes } & \text { Yes } \\ \text { No } & \text { Yes } & \text { No } & \text { Yes } \\ & & & \\ 4,121 & 4,121 & 4,121 & 4,121 \\ 0.876 & 0.899 & 0.901 & 0.915 \\ 12.68 & & & \end{array}$

Placebo coefficient $>0$

0.082

$(0.181)$

653

2

10

3,969

Placebo coefficient $>0$ and significant at 10 percent level Number of observations

Notes: To be classified as obese the BMI should be greater or equal than $30 \mathrm{~kg} / \mathrm{m} 2$. Each regression controls for covariates listed in Table 1: GDP growth, log of per capita GDP, percentage of population of age 0-14 and 15-64, enrollment in secondary school, and net migration. Standard errors are clustered at the country level. 


\section{Appendix 3. Event Studies Using Synthetic Control Methods}

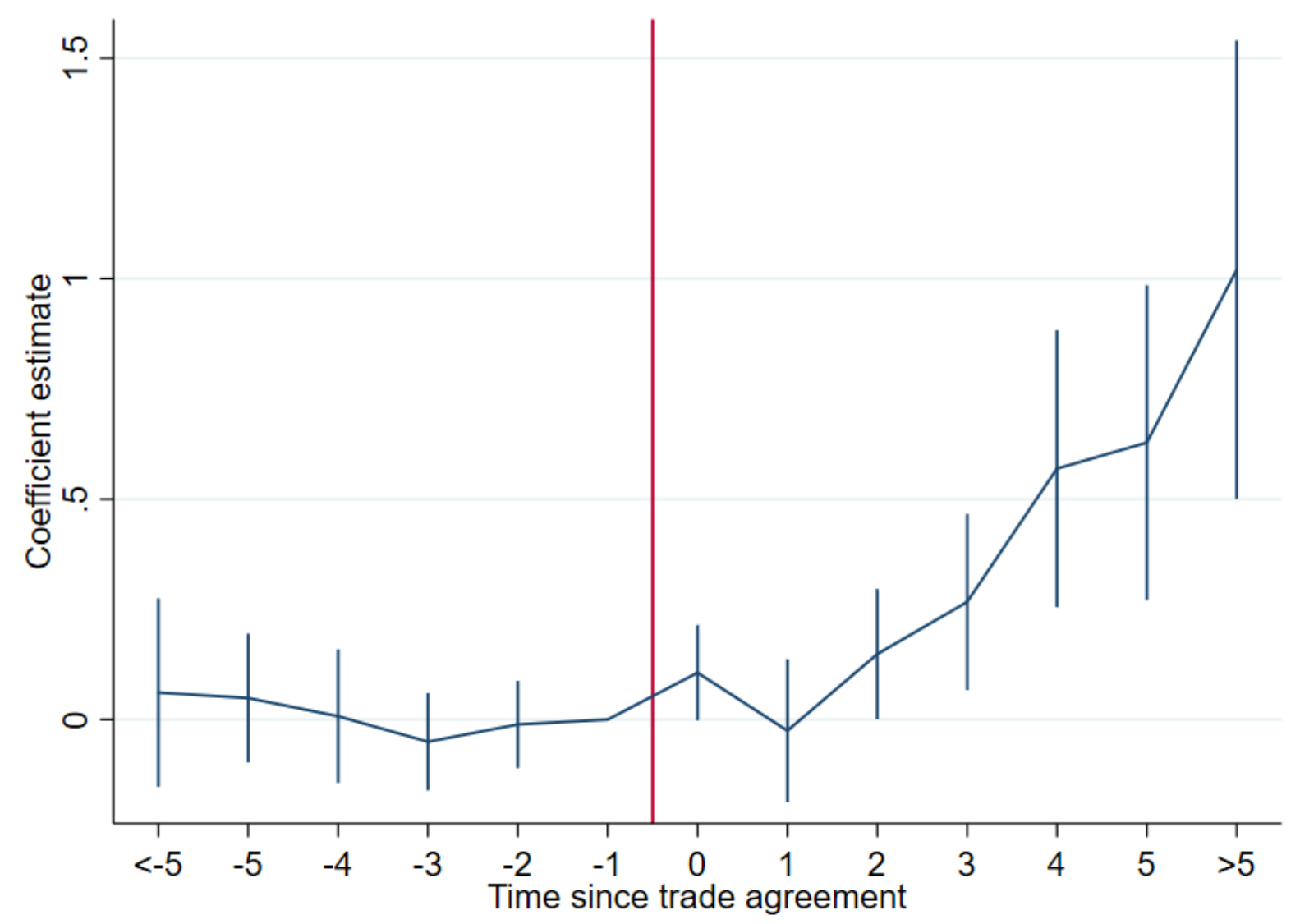

Notes: The graph show parameter estimates for the years before and after the change in free trade agreement from a regression that controls for country and year fixed effects as well as GDP growth, log of per capita GDP, percentage of population of age 0-14 and 15-64, enrollment in secondary school, and net migration, interaction between covariates and continent-specific time trends. Standard errors are clustered at the country level. Year -1 is the reference event and its coefficient is not estimated and thus equal to zero. 
Appendix 4. Synthetic Control Method: Free Trade Agreements on Obesity Rates, 1990-2016

Free trade $=1$

Country and year fixed effects

Continent-specific trend

Covariates interactions

Observations

R-squared

Mean obesity
(1)

(2)

(3)

(4)

$\begin{array}{rrrr}0.466^{* * *} & 0.266^{* *} & 0.333^{* * *} & 0.153^{*} \\ (0.168) & (0.116) & (0.120) & (0.0840)\end{array}$

$\begin{array}{rrrr}\text { Yes } & \text { Yes } & \text { Yes } & \text { Yes } \\ \text { No } & \text { No } & \text { Yes } & \text { Yes } \\ \text { No } & \text { Yes } & \text { No } & \text { Yes } \\ & & & \\ 776 & 776 & 776 & 776 \\ 0.9604 & 0.9758 & 0.9746 & 0.9824 \\ 17.49 & & & \end{array}$

Notes: To be classified as obese the BMI should be greater or equal than $30 \mathrm{~kg} / \mathrm{m} 2$. Each regression controls for covariates listed in Table 1: GDP growth, log of per capita GDP, percentage of population of age 0-14 and 15-64, enrollment in secondary school, and net migration. Standard errors are clustered at the country level. 
Appendix 5. Event Study: Free Trade Agreement and Sugar Consumption, 1990-2016

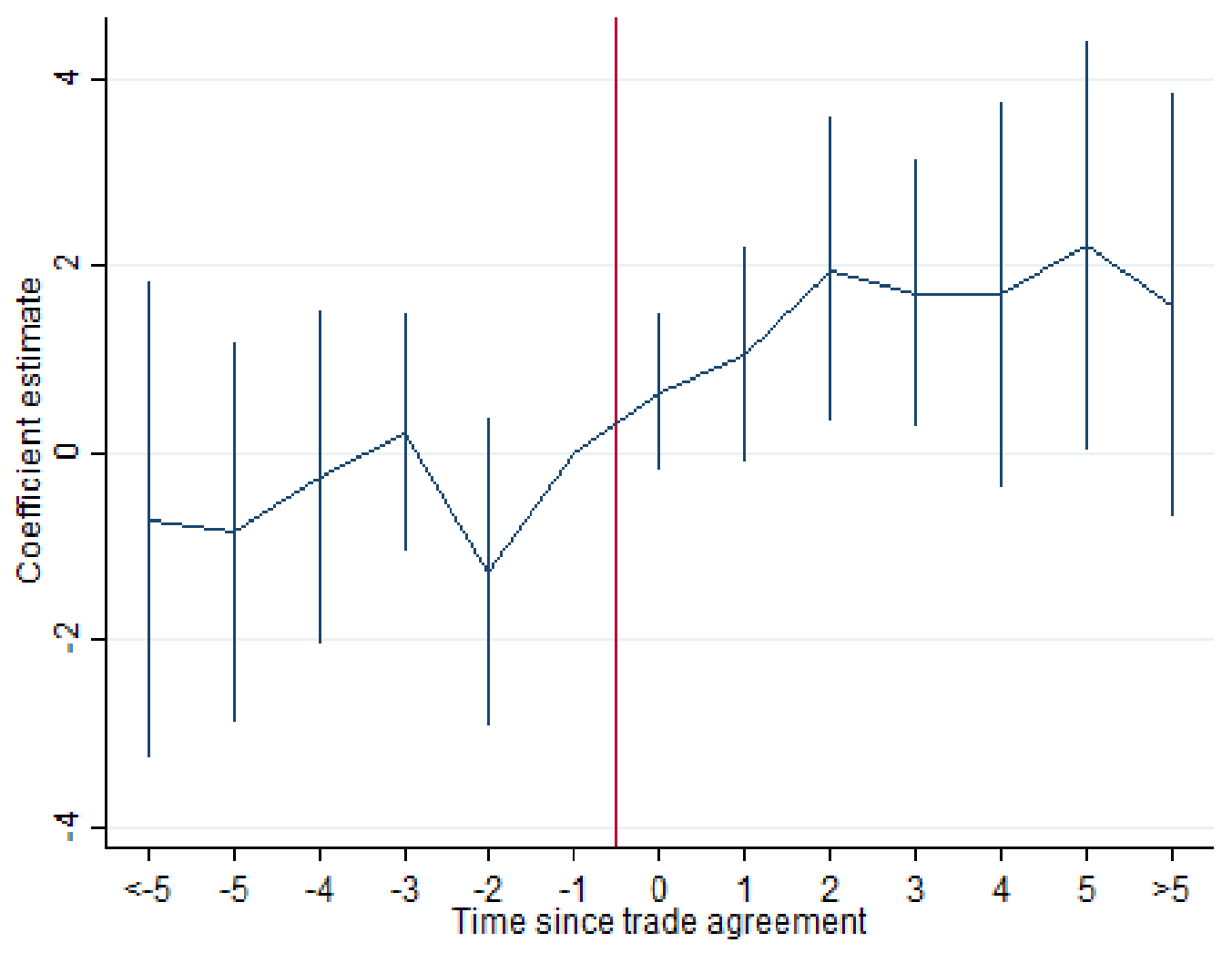

Notes: The graphs show parameter estimates for the years before and after the change in free trade agreement from a regression that controls for country and year fixed effects all covariates listed in Table 1. Year -1 is the omitted and thus it is the reference event and its coefficient is not estimated and thus equal to zero. 